\title{
Simple HPLC Analysis of Hinokitiol in Skin Lotion with Visible Light Detection after Pre-Column Dabsylation
}

\author{
Yasuhiko Higashi*, Shunsuke Tohda \\ Department of Analytical Chemistry, Faculty of Pharmaceutical Sciences, Hokuriku University, Kanazawa, Japan \\ Email: *y-higashi@hokuriku-u.ac.jp
}

How to cite this paper: Higashi, Y. and Tohda, S. (2017) Simple HPLC Analysis of Hinokitiol in Skin Lotion with Visible Light Detection after Pre-Column Dabsylation. American Journal of Analytical Chemistry, 8, 345-354.

https://doi.org/10.4236/ajac.2017.85026

Received: March 30, 2017

Accepted: May 14, 2017

Published: May 17, 2017

Copyright $\odot 2017$ by authors and Scientific Research Publishing Inc. This work is licensed under the Creative Commons Attribution International License (CC BY 4.0).

http://creativecommons.org/licenses/by/4.0/

cC) $\underset{\mathrm{EY}}{ }$ Open Access

\begin{abstract}
Hinokitiolis frequently added to personal care products as an antibacterial agent. We previously established an HPLC-UV method for determination of hinokitiol in skin lotion after pre-column derivatization with 4-fluoro-7-nitro2,1,3-benzoxadiazole. However, the labeling reagent is expensive, and derivatives of degradation products of parabens, which may be added to skin lotion as general preservatives, interfered with the peak of the hinokitiol derivative. In this study, the concentration of hinokitiol in skin lotions was determined by HPLC with a visible light detector $(450 \mathrm{~nm})$ after pre-column derivatization with 4-(dimethylamino)azobenzene-4'-sulfonyl chloride (Dabsyl-Cl), a more economical reagent. A standard curve was obtained after derivatization with Dabsyl-Cl in borate buffer ( $\mathrm{pH} 9.5)$ at $55^{\circ} \mathrm{C}$ for $10 \mathrm{~min}$. The retention time of Dabsyl-hinokitiol was $6.8 \mathrm{~min}$. The calibration plot was linear in the range of 1.25 to $40 \mu \mathrm{g} / \mathrm{mL}$ with a $r^{2}$ value of 0.9991 , and the lower limit of quantification and detection were $0.60 \mu \mathrm{g} / \mathrm{mL}$ (absolute amount of $0.86 \mathrm{ng} / 20 \mu \mathrm{L}$ injection, signal-to-noise ratio of $10: 1$ ) and $0.18 \mu \mathrm{g} / \mathrm{mL}$ (absolute amount of 0.26 $\mathrm{ng} / 20 \mu \mathrm{L}$ injection, signal-to-noise ratio of 3:1), respectively. The coefficient of variation was less than $8.8 \%$. Seven Dabsyl-paraben derivatives showed little interference with the peak of Dabsyl-hinokitiol. The developed system was used to determine the content of hinokitiol in two skin lotions. Additionrecovery tests gave satisfactory results.
\end{abstract}

\section{Keywords}

Hinokitiol, 4-(Dimethylamino)Azobenzene-4'-Sulfonyl Chloride, Derivatization, Paraben, Skin Lotion 


\section{Introduction}

Hinokitol (Figure 1, $\beta$-thujaplicin, 4-isopropyl-2-hydroxycyclopenta-2,4,6-trien1 -one) is a naturally occurring toxic tropolone, containing an unsaturated seven-membered carbon ring. The compound is found in heartwood of several cupressaceous plants, such as western red cedar (Thujaplicata), eastern white cedar (Thuja occidentalis), hinoki cypress (Chamaecypraisobtusa), and hiba (Thujopsis dolabrata) [1] [2]. It has a potent anti-bacterial activity (minimum inhibitory concentration of $0.2 \mu \mathrm{g} / \mathrm{mL}$ for Staphylococcus epidermis and Daedalea dickinsii) [2] [3], and is used as an additive in various cosmetic products, including skin lotion and body soap.

GC and HPLC analyses of hinokitiol are not straightforward, because the tropolone ring has chelating ability, is relatively unstable and is adsorbed on the stationary phase. However, quantitative determinations of hinokitiol by GC and capillary GC have been performed after derivatization with trimethylsilyl chloride and with diazomethane, respectively [1] [4]. Hanafusa et al. [5] determined hinokitiol in cosmetics by HPLC with UV detection following formation of a hinokitiol-copper (II) complex by addition of copper (II) to the mobile phase, but they did not describe the sensitivity of the method. Also, waste containing copper (II) is toxic. Endo et al. [6] reported a sensitive HPLC determination of hinokitiol after difluoroborane derivatization; the detection limit was $40 \mathrm{pg}$ of hinokitiol. Dyrskov et al. [7] determined hinokitiol by capillary zone electrophoresis, which gave a detection limit of $0.21 \mu \mathrm{M}$. An HPLC-dual UV (240 and $345 \mathrm{~nm}$ ) method of hinokitiol determination in personal care products was established using a reversed-phase $\mathrm{C}_{4}$ column, providing detection limits of 0.005 $\mu \mathrm{g} / \mathrm{mL}$ (absolute amount of $1 \mathrm{ng}$ ) and $0.01 \mu \mathrm{g} / \mathrm{mL}$ (absolute amount of $2 \mathrm{ng}$ ) at 240 and $345 \mathrm{~nm}$, respectively [8]. Also, a simple determination method of hinokitiol in a skin lotion was recently established by HPLC-UV using 4-fluoro-7nitro-2,1,3-benzoxadiazole(NBD-F) as a pre-column UV-labeling agent [9]. However, parabens (general preservatives often added to cosmetics) or their degradation products generated interfering peaks, so the method was only appropriate for hinokitiol analysis in paraben-free samples. In addition, the labeling reagent is expensive, although the method is sensitive (detection limit: $0.33 \mathrm{ng}$ ). More

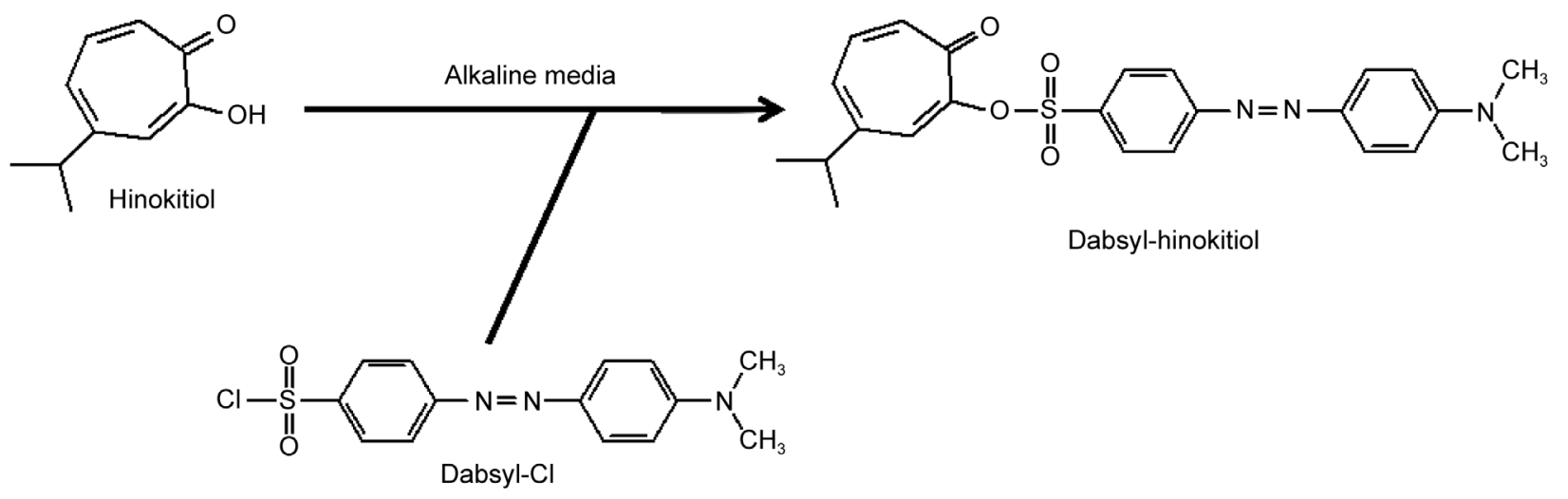

Figure 1. Scheme of hinokitiol derivatization with Dabsyl-Cl. 
seriously, hinokitiol determination in tested cosmetics showed poor reproducibility [8] [9].

The aim of the present study was to develop a simple, sensitive and economical assay of hinokitiol that would be suitable for quality assessment of personal care products containing parabens or their degradation products. We focused on 4-(dimethylamino)azobenzene-4'-sulfonyl chloride (Dabsyl-Cl) as a visible light (VIS) labelling agent for primary or secondary amino and phenolic hydroxyl groups [10] [11]. The sulfonyl chloride group of Dabsyl-Cl reacts with the hydroxyl group of hinokitiol $\left(\mathrm{p} K_{\mathrm{a}} 7.29\right.$ at $25^{\circ} \mathrm{C}$ [6]) in alkaline media as shown in Figure 1. Here, we describe an HPLC assay of hinokitiol in personal care products with VIS detection after pre-column derivatization with Dabsyl-Cl. We confirmed that there was little interference from paraben-related peaks.

\section{Materials and Methods}

\subsection{Materials}

Hinokitiol, Dabsyl-Cl, methyl 4-hydroxybenzoate, ethyl 4-hydroxybenzoate, propyl 4-hydroxybenzoate, isopropyl 4-hydroxybenzoate, butyl 4-hydroxybenzoate, isobutyl 4-hydroxybenzoateand benzyl 4-hydroxybenzoate were obtained from Tokyo Chemical Industry Co., Ltd. (Tokyo, Japan). General reagents were obtained from Wako Pure Chemical Industries (Osaka, Japan). Skin lotions A and B were purchased from a market in Kanazawa city, Ishikawa Pref., Japan. Skin lotion A contained hinokitiol at $0.05 \mathrm{~g} / 100 \mathrm{~mL}$ (labeled concentration). Skin lotion $\mathrm{B}$ also contained hinokitiol, but the level was not stated on the label.

\subsection{Chromatographic Conditions}

The HPLC system consisted of a model LC-10ATvp pump (Shimadzu, Kyoto, Japan), a Rheodyne injection valve (Cotati, CA, U.S.A.) with a $20-\mu \mathrm{L}$ loop, and a model SPD-10Avp UV/VIS detector (Shimadzu) operating at $450 \mathrm{~nm}$. The HPLC column ( $\mathrm{C}_{18}$-MS-II, Nacalaitesque, Kyoto, Japan) was $150 \mathrm{~mm} \times 3.0 \mathrm{~mm}$ i.d., containing $5 \mu \mathrm{m}$ particles of $\mathrm{C}_{18}$ packing material. Quantification of peaks was performed using a Chromatopac Model C-R8A integrator (Shimadzu). The mobile phase was prepared by addition of acetonitrile $(720 \mathrm{~mL})$ to $280 \mathrm{~mL}$ of Milli-Q water containing trifluoroacetic acid $(0.1 \mathrm{v} / \mathrm{v} \%)$. The samples were eluted from the column at room temperature at a flow rate of $0.40 \mathrm{~mL} / \mathrm{min}$.

\subsection{Preparation of Standard Solutions}

A stock solution of hinokitiol $(400 \mu \mathrm{g} / \mathrm{mL})$ in $5 \%$ ethanol was prepared in dark glass bottle and stored at $4{ }^{\circ} \mathrm{C}$. It was diluted with water to prepare working solutions of $0,1.25,2.5,5,10,20$ and $40 \mu \mathrm{g} / \mathrm{mL}$.

\subsection{Derivatization}

Ultrapure water was obtained from a Milli-Q water purification system (Simplicity UV, Millipore Corporation, Bedford, MA, U.S.A.). Borate buffer (0.1 M) 
was adjusted to $\mathrm{pH} 9.5$ by addition of $\mathrm{NaOH}$. Borate buffer $(50 \mu \mathrm{L})$ was added to each working standard solution $(50 \mu \mathrm{L})$, and then saturated Dabsyl-Cl solution in acetonitrile (supernatant after centrifugation of $1 \mathrm{mg} / \mathrm{mL}$ suspension, $300 \mu \mathrm{L}$ ) was added. The mixture was vortexed and allowed to react for $10 \mathrm{~min}$ at $55^{\circ} \mathrm{C}$. Ice-cold saturated L-aspartate solution (supernatant after centrifugation of 5 $\mathrm{mg} / \mathrm{mL}$ of L-aspartate suspension, $300 \mu \mathrm{L}$ ) was added to stop the reaction. Then, an aliquot $(20 \mu \mathrm{L})$ of the solution was injected into the HPLC system.

\subsection{Application to Skin Lotion Samples and Addition-Recovery Tests}

Test skin lotion A $(0.25 \mathrm{~mL})$ and test skin lotion $\mathrm{B}(1.0 \mathrm{~mL})$ were each diluted to $20 \mathrm{~mL}$ with water. These diluted samples were analyzed after derivatization as described above. Addition-recovery tests were carried out to assess the accuracy of the method by spiking each skin lotion with hinokitiol $(100 \mu \mathrm{g}, 250 \mu \mathrm{L}$ of stock solution), and the hinokitiol concentration in an aliquot of $50 \mu \mathrm{L}$ was determined. Recovery was calculated as follows:

$$
\operatorname{Recovery}(\%)=\frac{(\text { Total amount after spiking })-(\text { Spiked amount })}{(\text { Original amount })} \times 100
$$

\section{Results and Discussion}

\subsection{Derivatization of Hinokitiol with Dabsyl-Cl}

For the time-course study, the reaction time was set at 1,3,5, 10 and $15 \mathrm{~min}$ at $55^{\circ} \mathrm{C}$. Hinokitiol $(50 \mu \mathrm{L}, 40 \mu \mathrm{g} / \mathrm{mL})$, borate buffer $(50 \mu \mathrm{L}, \mathrm{pH} 9.5)$ and saturated Dabsyl-Cl solution in acetonitrile $(300 \mu \mathrm{L})$ were mixed as described in Materials and Methods. The derivatization of hinokitiol reached a plateau at $5 \mathrm{~min}$ (more than $98 \%$ of the maximal peak area), and the peak area was maximalat $10 \mathrm{~min}$ (Figure 2). The peak area remained stable until $15 \mathrm{~min}$.

Temperature dependency was tested for the derivatization time of $5 \mathrm{~min}$, as shown in Figure 3. Reaction temperature was set at $50^{\circ} \mathrm{C}, 55^{\circ} \mathrm{C}, 60^{\circ} \mathrm{C}$, and $65^{\circ} \mathrm{C}$. The peak area of Dabsyl-hinokitiol was stable at $50^{\circ} \mathrm{C}$ to $60^{\circ} \mathrm{C}$, but decreased somewhat at $65^{\circ} \mathrm{C}$.

$\mathrm{pH}$ dependency ( $\mathrm{pH} 7.5$ to 10.0 ) was examined for the derivatization time of 5 min at $55^{\circ} \mathrm{C}$. Peak area of Dabsyl-hinokitiol was maximal at pH 9.5 (Figure 4). Under $\mathrm{pH} 8.5$, the peak area of the derivative was gradually decreased.

When half-saturated Dabsyl-Cl solution in acetonitrile was utilized under optimal conditions, the peak area was reduced to about $50 \%$ (data not shown).

Thus, we selected the derivatization time of $10 \mathrm{~min}$ at $55^{\circ} \mathrm{C}$ and $\mathrm{pH} 9.5$ with saturated Dabsyl-Cl solution in acetonitrile for the assay.

\subsection{Chromatogram}

Figure 5 shows typical chromatograms obtained from (a) blank and (b) standard sample $(10 \mu \mathrm{g} / \mathrm{mL})$. The retention time of Dabsyl-hinokitiol was $6.8 \mathrm{~min}$. The running time was $15 \mathrm{~min}$. 


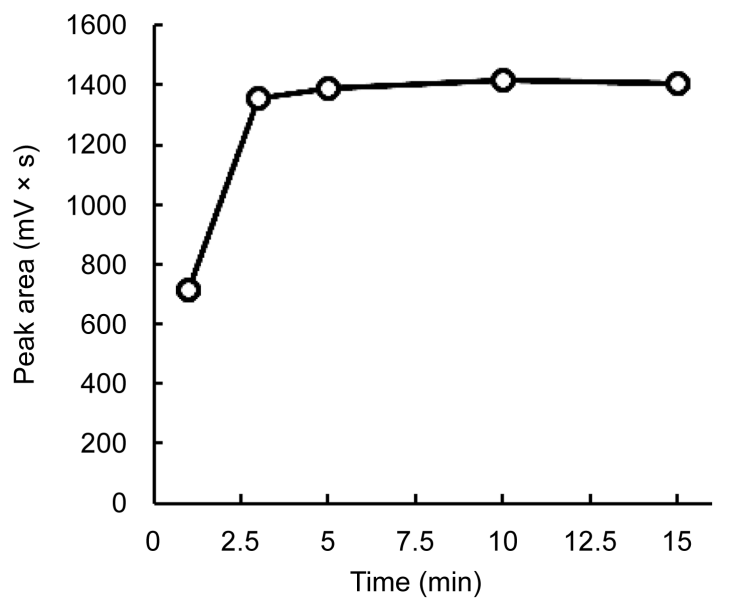

Figure 2. Time course of formation of the Dabsyl derivative of hinokitiol. Standard sample $(40 \mu \mathrm{g} / \mathrm{mL})$ was reacted with Dabsyl-Cl in borate buffer, $\mathrm{pH} 9.5$, at $55^{\circ} \mathrm{C}$. Data are expressed as mean values of two experiments.

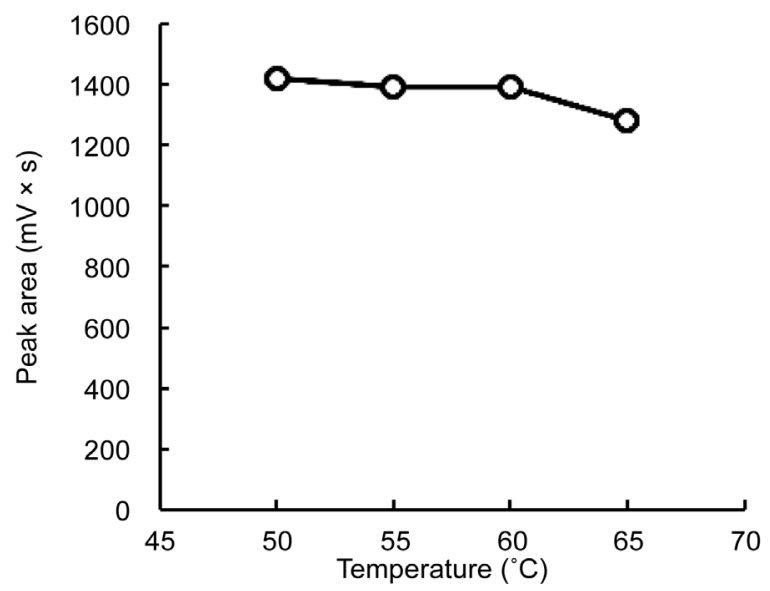

Figure 3. Temperature dependency of formation of the Dabsyl derivative of hinokitiol. Standard sample $(40 \mu \mathrm{g} / \mathrm{mL})$ was reacted with Dabsyl-Cl for $10 \mathrm{~min}$ in borate buffer at $\mathrm{pH}$ 9.5. Data are expressed as mean values of two experiments.

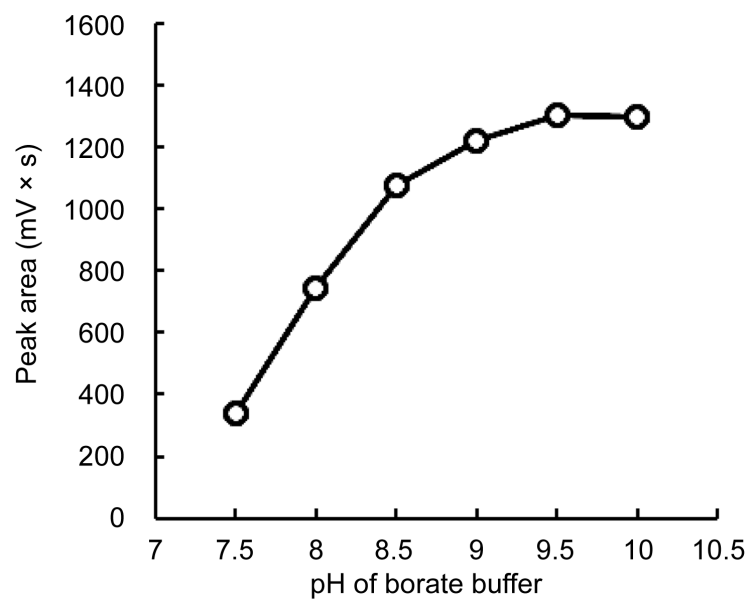

Figure 4. $\mathrm{pH}$ dependency of formation of the Dabsyl derivative of hinokitiol. Standard sample $(40 \mu \mathrm{g} / \mathrm{mL})$ was reacted with Dabsyl- $\mathrm{Cl}$ for $10 \mathrm{~min}$ at $55^{\circ} \mathrm{C}$ in borate buffer at various $\mathrm{pH}$ values. Data are expressed as mean values of two experiments. 
(a)

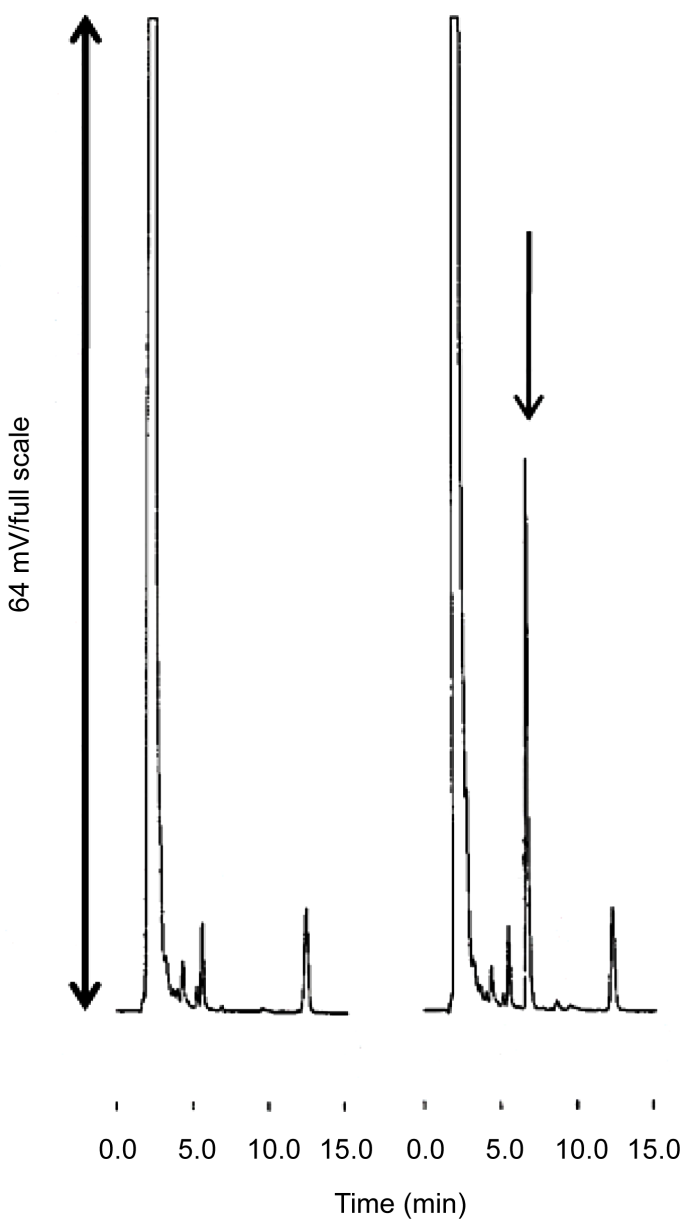

Figure 5. Typical chromatograms of blank (a) and standard sample ((b), $10 \mu \mathrm{g} / \mathrm{mL})$ after derivatization with Dabsyl-Cl. Samples were reacted with Dabsyl-Cl for 10 min in borate buffer, $\mathrm{pH} 9.5$, at $55^{\circ} \mathrm{C}$. Retention time of Dabsyl-hinokitiol derivative: $6.8 \mathrm{~min}$ (arrowed peak).

\subsection{Standard Curves of Hinokitiol}

A standard curve was constructed by plotting integrated peak area vs. concentration of hinokitiol. The plot was linear $(y=33.95 x+3.03)$ in the range of 1.25 to $40 \mu \mathrm{g} / \mathrm{mL}$ with an $r^{2}$ value of 0.9991 . The values of the lower limits of quantification and detection were $0.60 \mu \mathrm{g} / \mathrm{mL}$ (absolute amount of $0.86 \mathrm{ng} / 20 \mu \mathrm{L}$ injection, signal-to-noise ratio of $10: 1$ ) and $0.18 \mu \mathrm{g} / \mathrm{mL}$ (absolute amount of $0.26 \mathrm{ng}$ / $20 \mu \mathrm{L}$ injection, signal-to-noise ratio of 3:1), respectively. As shown in Table 1 , the sensitivity (absolute amount) of the presented method can be classed as moderate, compared with previously reported methods [6] [7] [8] [9]. However, it was about 1.3- to 7.7-fold better than that of our previous method [8] [9].

\subsection{Precision and Accuracy}

Precision and accuracy for intra-day and inter-day assays of hinokitiol are shown in Table 2 . In the intra-day assay, the range of standard deviation was within $5.2 \%$ to $7.7 \%$ of the mean, and recoveries were within the range of $93.3 \%$ 
Table 1. Sensitivity of various methods for determination of hinokitiol.

\begin{tabular}{llc}
\hline \multicolumn{1}{c}{ Methods } & \multicolumn{1}{c}{ Limit of detection } & Reference \\
\hline $\begin{array}{l}\text { HPLC-UV (derivatization with } \\
\text { difluoroborane) }\end{array}$ & Absolute amount of $0.040 \mathrm{ng}$ & {$[6]$} \\
$\begin{array}{l}\text { Capillary zone electrophoresis- } \\
\text { diode array detector }\end{array}$ & $\begin{array}{l}\text { Not described absolute amount; } \\
0.034 \mu \mathrm{g} / \mathrm{mL} \text { as concentration }\end{array}$ & {$[7]$} \\
& Absolute amount of $1 \mathrm{ng}$ (at $240 \mathrm{~nm}$ ); & \\
$\begin{array}{l}\text { HPLC-UV (no derivatization, } \\
\text { i.e. direct injection) }\end{array}$ & $0.005 \mu \mathrm{g} / \mathrm{mL}$ as concentration \\
& Absolute amount of $2 \mathrm{ng}($ at $345 \mathrm{~nm}$ ); & {$[8]$} \\
HPLC-UV (derivatization with & $0.01 \mu \mathrm{g} / \mathrm{mL}$ as concentration \\
NBD-F) & $\begin{array}{l}\text { Absolute amount of } 0.33 \mathrm{ng} ; \\
0.05 \mu \mathrm{g} / \mathrm{mL} \text { as concentration }\end{array}$ & {$[9]$} \\
HPLC-VIS (derivatization with & Absolute amount of $0.26 \mathrm{ng} ;$ \\
Dabsyl-Cl) & $0.18 \mu \mathrm{g} / \mathrm{mL}$ as concentration & This paper \\
\hline
\end{tabular}

Table 2. Intra- and inter-day assay reproducibility for determination of hinokitiol.

\begin{tabular}{cccc}
\hline Concentration $(\mu \mathrm{g} / \mathrm{mL})$ & Measured $(\mathrm{mg} / \mathrm{L}$, Mean \pm S.D., $n=5)$ & C.V. $(\%)$ & Recovery $(\%)$ \\
\hline$\underline{\text { Intra-day assay }}$ & & & \\
1.25 & $4.17 \pm 0.09$ & 7.7 & 93.6 \\
5 & $42.5 \pm 2.2$ & 5.6 & 93.4 \\
40 & & 5.2 & 106.3 \\
$\underline{\text { Inter-day assay }}$ & $1.13 \pm 0.10$ & & \\
1.25 & $4.64 \pm 0.33$ & 8.8 & 90.4 \\
5 & $41.6 \pm 2.6$ & 7.1 & 92.8 \\
40 & & 6.3 & 104.0 \\
\hline
\end{tabular}

to $106.3 \%$. In the inter-day assay, the range of standard deviation was within $6.3 \%$ to $8.8 \%$ of the mean, and recoveries were within the range of $90.4 \%$ to $104.0 \%$.

\subsection{Interference}

Cosmetics generally contain several parabensas preservatives [12] [13] [14]. Therefore, interference with the detection of Dabsyl-hinokitiol derivative by seven parabens (methyl 4-hydroxybenzoate, ethyl 4-hydroxybenzoate, propyl 4-hydroxybenzoate, isopropyl 4-hydroxybenzoate, butyl 4-hydroxybenzoate, isobutyl 4-hydroxybenzoateand benzyl 4-hydroxybenzoate, each $0.2 \mu \mathrm{g} / \mathrm{mL}$ in $1 \%$ acetonitrile) was investigated. Derivatization was performed as described above, and the running time was set at $35 \mathrm{~min}$. Table 3 summarizes the retention times of the seven Dabsyl-paraben derivatives (Dabsyl-methyl 4-hydroxybenzoate, Dabsyl-ethyl 4-hydroxybenzoate, Dabsyl-isopropyl 4-hydroxybenzoate, 
Table 3. Retention times of paraben derivatives tested for interference with Dabsyl-hinokitiol peak.

\begin{tabular}{cc}
\hline Dabsyl derivatives & Retention time (min) \\
\hline Dabsyl-hinokitiol & 6.8 \\
Dabsyl-methyl 4-hydroxybenzoate & 11.7 \\
Dabsyl-ethyl 4-hydroxybenzoate & 16.1 \\
Dabsyl-isopropyl 4-hydroxybenzoate & 21.9 \\
Dabsyl-propyl 4-hydroxybenzoate & 22.4 \\
Dabsyl-benzyl 4-hydroxybenzoate & 26.3 \\
Dabsyl-isobutyl 4-hydroxybenzoate & 30.3 \\
Dabsyl-butyl 4-hydroxybenzoate & 32.0 \\
\hline
\end{tabular}

Dabsyl-propyl 4-hydroxybenzoate, Dabsyl-benzyl 4-hydroxybenzoate, Dabsylisobutyl 4-hydroxybenzoate and Dabsyl-butyl 4-hydroxybenzoate). A slight peak (under lower limit of quantification of hinokitiol) was observed at $6.8 \mathrm{~min}$, and the retention times of the major peaks of the seven Dabsyl-paraben derivatives were more than $11.5 \mathrm{~min}$. These data suggests that parabens would not interfere with hinokitiol determination in this system. Thus, Dabsyl-Cl is a more appropriate derivatization reagent than NBD-F.

\subsection{Analysis of Skin Lotions}

Figure 6 shows typical chromatograms obtained from skin lotions A and B. The peak of Dabsyl-hinokitiol was detected at $6.8 \mathrm{~min}$ in both samples A and B.

The established method was used to determine hinokitiol concentration in skin lotion sample A and in samples spiked with standards. As shown in Table 4, the concentration of hinokitiol in the skin lotion was found to be $559 \pm 56$ $\mu \mathrm{g} / \mathrm{mL}$ (range, 499 to $614 \mu \mathrm{g} / \mathrm{mL}$ ). Skin lotion A contained hinokitiol at 0.05 $\mathrm{g} / 100 \mathrm{~mL}$ according to the label. It is possible that parabens contributed to the slight difference, because peaks of paraben derivatives were observed at 16.1 and 26.3 min (data not shown). Recovery of spiked hinokitiol from the cosmetic was $87.4 \% \pm 5.7 \%$ (range, $83.2 \%$ to $96.1 \%$ ). Thus, our result is consistent with the labeled concentration. Next, the established method was used to determine hinokitiol in skin lotion sample B and in samples spiked with standards. No peaks due to parabens were observed (data not shown). The concentration of hinokitiol in the skin lotion was found to be $76.2 \pm 2.5 \mu \mathrm{g} / \mathrm{mL}$ (range, 73.1 to 78.3 $\mu \mathrm{g} / \mathrm{mL}$ ). Recovery of spiked hinokitiol was $86.2 \% \pm 3.5 \%$ (range, $83.7 \%$ to 91.3\%).

\section{Conclusion}

We have developed a simple HPLC-VIS method for determination of hinokitiolin skin lotion after pre-column derivatization with Dabsyl-Cl. The sensitivity 
(a)

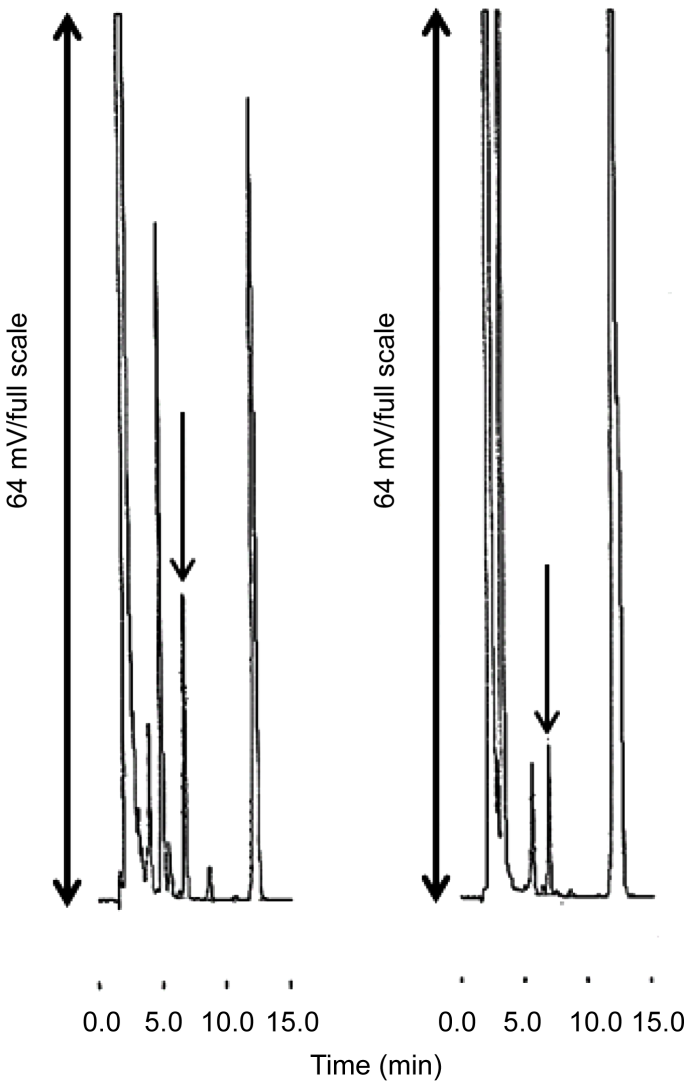

Figure 6. Typical chromatograms of skin lotion sample ((a), $0.25 \mathrm{~mL} / 20 \mathrm{~mL})$ and skin lotion sample ((b), $1.0 \mathrm{~mL} / 20 \mathrm{~mL})$ after derivatization with Dabsyl-Cl. Samples were reacted with Dabsyl-Cl for $10 \mathrm{~min}$ in borate buffer, $\mathrm{pH} 9.5$, at $55^{\circ} \mathrm{C}$. Retention time of Dabsyl-hinokitiol derivative: $6.8 \mathrm{~min}$ (arrowed peak).

Table 4. Level of hinokitiol in skin lotions (A and B) and recovery of spiked hinokitiol $(100 \mu \mathrm{g})$.

\begin{tabular}{ccccc}
\hline Assay & \multicolumn{2}{c}{ Skin lotion A } & \multicolumn{2}{c}{ Skin lotion B } \\
\hline & Content $(\mu \mathrm{g} / \mathrm{mL})$ & Recovery $(\%)$ & Content $(\mu \mathrm{g} / \mathrm{mL})$ & Recovery $(\%)$ \\
\hline Day 1 & 608 & 84.7 & 76.5 & 87.1 \\
Day 2 & 614 & 85.7 & 73.1 & 84.0 \\
Day 3 & 499 & 87.2 & 74.9 & 83.7 \\
Day 4 & 536 & 83.2 & 78.3 & 91.3 \\
Day 5 & 538 & 96.1 & 78.1 & 85.1 \\
Ave. \pm S.D. & $559 \pm 56$ & $87.4 \% \pm 5.7 \%$ & $76.2 \pm 2.5$ & $86.2 \% \pm 3.5 \%$ \\
(R.S.D.) & $(10.0 \%)$ & $(6.5 \%)$ & $(3.3 \%)$ & $(4.1 \%)$ \\
\hline
\end{tabular}

of the assay can be classed as moderate. This system showed little interference from parabens, in contrast to the previously reported assay using NBD-F [9]. The new system should be suitable for quality-control monitoring of hinokitiol levels in cosmetics containing parabens. 


\section{References}

[1] Nault, J. (1987) A Capillary Gas Chromatographic Method for Thujaplicins in Western Red Cedar Extractives. Wood Science and Technology, 21, 311-316. https://doi.org/10.1007/BF00380198

[2] Inamori, Y., Shinohara, S., Tsujibo, H., Okabe, T., Morita, Y., Sakagami, Y., Kumeda, Y. and Ishida, N. (1999) Antimicrobial Activity and Metalloprotease Inhibition of Hinokitiol-Related Compounds, the Constituents of Thujopsis Dolabrata S. and Z. Hondai MAK. Biological and Pharmaceutical Bulletin, 22, 990-993. https://doi.org/10.1248/bpb.22.990

[3] Inamori, Y., Sakagami, Y., Morita, Y., Shibata, M., Sugiura, M., Kumeda, Y., Okabe, T., Tsujibo, H. and Ishida, N. (2000) Antifungal Activity of Hinokitiol-Related Compounds on Wood-Rotting Fungi and Their Insecticidal Activities. Biological and Pharmaceutical Bulletin, 23, 995-997. https://doi.org/10.1248/bpb.23.995

[4] Johnson, E.L. and Cserjesi, A.J. (1975) Gas-Liquid Chromatography of Some Tropolone-TMS Ethers. Journal of Chromatography, 107, 388.

https://doi.org/10.1016/0021-9673(75)80015-X

[5] Hanafusa, F., Nakamura, K., Togano, S. and Ohta, T. (1989) Determination of Hinokitiol in Cosmetic Products by HPLC. Bunseki Kagaku, 38, 124-128.

https://doi.org/10.2116/bunsekikagaku.38.3_124

[6] Endo, M., Mizutani, T., Matsumura, M., Moriyasu, M., Ichimaru, M., Kato, A. and Hashimoto, Y. (1988) High-Performance Liquid Chromatographic Determination of Hinokitiol in Cosmetics by the Formation of Difluoroborane Compounds. Journal of Chromatography, 455, 430-433.

https://doi.org/10.1016/S0021-9673(01)82152-X

[7] Dyrskov, L., Strobel, B.W., Svensmark, B. and Hansen, H.C. (2004) Beta-Thujaplicin: New Quantitative CZE Method and Adsorption to Goethite. Journal of Agricultural and Food Chemistry, 52, 1452-1457. https://doi.org/10.1021/jf030652h

[8] Higashi, Y. Sakata, M. and Fujii, Y. (2009) High-Performance Liquid Chromatography with Dual-Wavelength Ultraviolet Detection for Measurement of Hinokitiol in Personal Care Products. Journal of Cosmetic Science, 60, 519-525.

[9] Higashi, Y. and Fujii, Y. (2013) Determination of Hinokitiol in a Skin Lotion by HPLC-UV Analysis after Pre-Column Derivatization with 4-Fluoro-7-Nitro-2,1,3Benzoxadiazole. Journal of Cosmetic Science, 64, 381-389.

[10] Gao, R., Higashi, Y. and Fujii, Y. (2010) Simple Determination of Fluoxetine and Norfluoxetine in Human Serum and Urine by Dabsylation Followed by HPLC with Visible Light Detection. Journal of Liquid Chromatography \& Related Technologies, 33, 1405-1415. https://doi.org/10.1080/10826076.2010.489435

[11] Lacroix, C. and Saussereau, E. (2012) Fast Liquid Chromatography/Tandem Mass Spectrometry Determination of Cannabinoids in Micro Volume Blood Samples after Dabsyl Derivatization. Journal of Chromatography B, 905, 85-95.

https://doi.org/10.1016/j.jchromb.2012.08.006

[12] Huang, J.Q., Hu, C.C. and Chiu, T.C. (2013) Determination of Seven Preservatives in Cosmetic Products by Micellar Electrokinetic Chromatography. International Journal of Cosmetic Science, 35, 346-353. https://doi.org/10.1111/ics.12040

[13] Charnock, C. and Finsrud, T. (2007) Combining Esters of Para-Hydroxy Benzoic Acid (Parabens) to Achieve Increased Antimicrobial Activity. Journal of Clinical Pharmacology and Therapeutics, 32, 567-572. https://doi.org/10.1111/j.1365-2710.2007.00854.x

[14] Darbre, P.D. and Harvey, P.W. (2008) Paraben Esters: Review of Recent Studies of Endocrine Toxicity, Absorption, Esterase and Human Exposure, and Discussion of Potential Human Health Risks. Journal of Applied Toxicology, 28, 561-578.

https://doi.org/10.1002/jat.1358 
Submit or recommend next manuscript to SCIRP and we will provide best service for you:

Accepting pre-submission inquiries through Email, Facebook, LinkedIn, Twitter, etc. A wide selection of journals (inclusive of 9 subjects, more than 200 journals)

Providing 24-hour high-quality service

User-friendly online submission system

Fair and swift peer-review system

Efficient typesetting and proofreading procedure

Display of the result of downloads and visits, as well as the number of cited articles Maximum dissemination of your research work

Submit your manuscript at: http://papersubmission.scirp.org/

Or contact ajac@scirp.org 